\title{
Repair of Composites: Design Choices Leading to Lower Life-Cycle Cost
}

\author{
Christos Kassapoglou ${ }^{1}$ (D) Konstantin Rangelov ${ }^{2}$. \\ Svilen Rangelov ${ }^{2}$
}

Received: 11 November 2016 / Accepted: 15 November 2016 / Published online: 29 November 2016

(C) The Author(s) 2016. This article is published with open access at Springerlink.com

\begin{abstract}
The fabrication cost of composite aircraft structures is revisited and the effect of part size on cost is examined with emphasis on design decisions which affect the ease of (bonded) repair and the total cost of the part and subsequent repairs. The case of moderately loaded stiffened fuselage or wing panels under compression is analysed in detail and the fabrication cost of the panel made as a single piece or as an assembly of smaller identical components or modules is determined. The cost of special purpose repairs for two different damage sizes is compared to removing and replacing damaged modules. Hand layup and automated processing are compared. It is found that for certain repair sizes removing and replacing modules leads to lower overall cost as compared to applying a special purpose repair.
\end{abstract}

Keywords Repair $\cdot$ Modular structure $\cdot$ Cost $\cdot$ Stiffened panel

\section{Introduction}

It is inevitable that some form of damage will occur during the lifetime of an aircraft. Whether it occurs during service or it is maintenance induced, damage manifests itself in many different forms. This is particularly important in the case of composite structures where damage takes the form of cracks, holes, delaminations, indentation, etc. and, for some types of damage such as delaminations, it is difficult and costly to detect. Just on holes, delaminations, and cracks recorded on composite structures in service, Gary and Riskalla [1] report 972 occurrences per one million flight hours. These are data from 1993 so they only cover composite structures at the time which were confined mostly to the empennage and wing fairings. Data from [1] for

Christos Kassapoglou

c.kassapoglou@tudelft.nl

1 Aerospace Structures \& Comp. Mechanics, Delft University of Technology, Delft, Netherlands

2 Dronamics Ltd., Sofia, Bulgaria 
three airlines (Delta, United, American) and one manufacturer (De Havilland) show that, on the average, there will be one damage incident manifesting itself as a crack or hole or delamination, per aircraft, per year (data from 1996 aircraft accumulating 6.6 million flight hours per year). Therefore, characterizing damage and understanding its effect on structural performance is critical. In addition, as composites find their way into increasingly higher percentages of an aircraft structure with the recent deployment of the B-787 and the A-350, this frequency will increase by more than a factor of ten as the area that could be damaged increases significantly. For example, the total surface area of wing and fuselage in B-787 is twelve times higher than the area of the empennage. It is, therefore, imperative to have reliable and efficient repair methods which can be used on damaged composite structure.

The focus of this work is bonded repair and, in particular how some aspects which will minimize the life-cycle cost can be built-into the design effort. The application is composite stiffened fuselage or wing skin which, for aerodynamic reasons, leads to a scarfed repair as the preferred choice.

Bonded repairs of composites have been studied in detail in the past. Soutis et al. [2] examined the failure modes of externally bonded repair patches under compression and found that fiber micro-buckling accompanied by matrix cracking and delaminations trigger final patch failure. Campilho et al. [3] used finite elements including cohesive behaviour to study damage initiation and growth in an adhesively bonded repair. Their results indicated that adhesive strength plays a bigger role than interface fracture toughness. Gunnion and Herszberg [4] used finite elements to study the effect of different parameters such as scarf angle, adhesive layer thickness and patch stacking sequence on the strength of a scarf joint in particular the effect on the peak stresses at the joint edges. The performance of a repair under fatigue loading and different environments was studied by Baker [5]. Optimization of repair design was done by Wang and Gunnion [6]. The importance of adhesive selection and surface treatment for long term repairs, in particular how they affect the relation between adhesive and adherend surface energy is discussed in detail by Baldan [7]. The effect of repair size, which relates direcly to the present work, was examined, for sandwich structures, by Tomblin et al. [8]. These are only a few representative contributions in the area of bonded and scarfed repairs. A more detailed review is provided by Katnam et al. [9].

The situation becomes significantly more complex when the cost of the composite structure and the cost of the repair are included. It is not guaranteed that structure with minimum fabrication cost will have minimum maintenance and, as a result, life-cycle cost. Depending on the location and size of damage to be repaired, the cost of the repair may be too high for a given design if special provisions have not been made to accommodate fast, robust, and low cost repairs. "Too high" here refers to the combination of part cost and repair cost for a given number of times that the part may have to be repaired during its lifetime.

Accurate cost modelling of composite structures and repairs is, therefore, very important. Ever since the important work by Lorenzana et al. [10] of Northrop Corporation in creating detailed cost equations for hand layup of composites, a number of models have been created proposing improvements and accounting for different fabrication processes. Gutowski and his co-workers $[11,12]$ proposed a physics-based model to calculate cost using the amount of information stored in each part of the structure. In addition, which has important implications for the work presented here, they examined the effect of part size on cost of composites [13].

The effect of part quality as assessed by non-destructive inspection was included in optimization of direct operating cost of composites by Kaufman et al. [14]. Special purpose software for cost estimation of composite structures such as SEER DFM has been developed 
and used successfully in generating optimum service life management strategies [15] and trading part size, learning curve effects, and cost [16]. The above are only representative of previous work in the area with direct bearing on the present work. A detailed review of cost models in composites can be found in [17].

The present work combines cost of composites and structural analysis and design and attempts to bring ease of repair and low fabrication and repair cost into the design process.

A stiffened composite structure typical of wing or fuselage under compression is selected as the application. It is designed taking some repair considerations into account and its cost is determined in detail. Then, two different scarf repairs for two different damage sizes are designed and their cost estimated in detail. The possibility of instead of a special-purpose repair removing and replacing an entire portion or module of the structure is examined and optimum part sizes which minimize manufacturing and repair cost are determined.

\section{Design of Composite Structure and Repair(S)}

A generic stiffened skin panel $2 \mathrm{~m}$ long by $1 \mathrm{~m}$ wide is used as the example. The design (ultimate) load is assumed to be $62 \mathrm{kN}$ in compression which, for a civil transport wing or fuselage, is a low to moderate applied load (62 N/mm of width). Seven equally spaced hat stiffeners are used. The situation is shown in Fig. 1.

The design process is well understood [18] so here only some highlights are given with emphasis on aspects relating to ease of repair. The dimensions of the cross-section of the hat stiffener can be the outcome of the design process or can be fixed a priori to reflect existing tooling and manufacturing process. Here, the latter was selected with the dimensions shown in

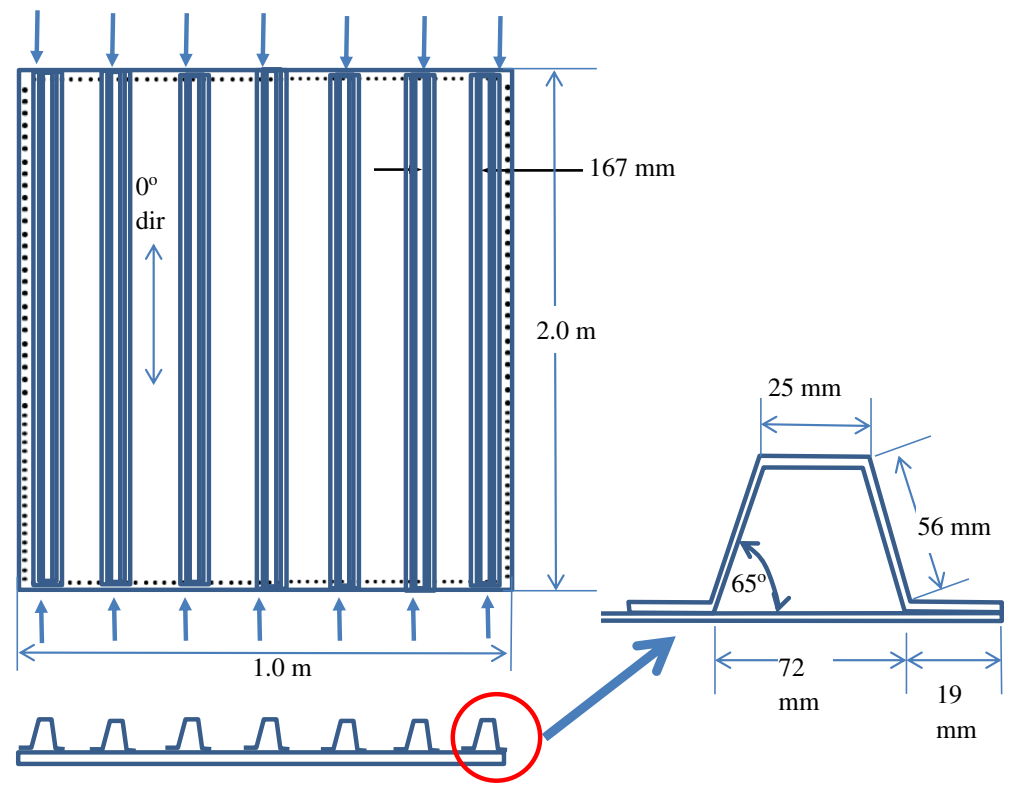

Fig. 1 Stiffened panel under compression (not to scale) 
Fig. 1. These dimensions, as will be shown later, accommodate repair splices along the hat stiffener axis. The structure is designed not to fail under the following failure modes:

- Strength of skin and stiffeners

- Buckling of skin between stiffeners (assumed as clamped along the stiffeners and simply supported at the loaded ends)

- Buckling of the entire panel assumed to be simply supported all around

- Column buckling of stiffeners

- Crippling of stiffener flanges and webs

- Bearing of fastener holes (the panel is assumed to be fastened to the next assembly around its edges)

Two types of prepreg material are used, uni-directional tape (UD) and plain weave fabric (PW). The properties are given in Table 1. To account for material scatter, environmental effects, and damage a strength knockdown factor of 0.416 is used [18]. The knockdown is not used on stiffness because if the stiffness of the panel were reduced load would be diverted to adjacent panels.

Following the procedures in [18], the panel was designed and the resulting layups and related information are given in Table 2. Plies designated as $( \pm 45)$ or $(0 / 90)$ refer to fabric plies. The layups are confined to combinations of $0,45,-45$ and 90 orientations. In addition, fabric plies are used on the outside of stiffeners and skin to improve impact resistance. Also, they are used in the stiffeners to blend the two flanges with the web and for ease of manufacturing as they can be bent more easily around the hat stiffener corners. UD plies with fibers parallel to the stiffener axis cannot be used to carry load around corners of the stiffener cross-section and plies with fibers perpendicular to the stiffener axis cannot bend around corners easily especially when concave (female) tooling is used.

As can be seen from Table 2, the lowest margin of safety of 0.0 occurs for stiffener crippling (stiffener canted web) followed by crippling of the stiffener flange next to the skin at 0.63 and bearing at 1.72 when $5 \mathrm{~mm}$ hole diameter and 4D hole spacing are used. The remaining margins are relatively high and this is done on purpose to facilitate the repair. For example, bay, panel, and stiffener buckling are relatively high because failure in these modes can be catastrophic as opposed to localized failure resulting from crippling or bearing. For this reason, crippling and bearing are

Table 1 Material properties

\begin{tabular}{lllll}
\hline Property & $\begin{array}{l}\text { UD } \\
\text { material }\end{array}$ & $\begin{array}{l}\text { PW } \\
\text { material }\end{array}$ & $\begin{array}{l}\text { UD with } \\
\text { knockdowns }\end{array}$ & $\begin{array}{l}\text { PW with } \\
\text { knockdowns }\end{array}$ \\
\hline $\mathrm{E}_{\mathrm{x}}(\mathrm{GPa})$ & 138 & 68.9 & 138 & 68.9 \\
$\mathrm{E}_{\mathrm{y}}(\mathrm{GPa})$ & 11.5 & 68.9 & 11.5 & 68.9 \\
$v_{\mathrm{xy}}$ & 0.29 & 0.05 & 0.29 & 0.05 \\
$\mathrm{G}_{\mathrm{xy}}(\mathrm{GPa})$ & 4.83 & 4.82 & 4.83 & 4.82 \\
$\mathrm{X}^{\mathrm{T}}(\mathrm{MPa})$ & 2068 & 965 & 1075 & 502 \\
$\mathrm{X}^{\mathrm{C}}(\mathrm{MPa})$ & 1723 & 862 & 896 & 448 \\
$\mathrm{Y}^{\mathrm{T}}(\mathrm{MPa})$ & 89.6 & 827 & 46.6 & 430 \\
$\mathrm{Y}^{\mathrm{c}}(\mathrm{MPa})$ & 358 & 793 & 186 & 412 \\
$\mathrm{~S}(\mathrm{MPa})$ & 117 & 126 & 60.9 & 65.6 \\
$\mathrm{~F}_{\text {bru }}(\mathrm{MPa})$ & 700 & 700 & 292 & 292 \\
$\mathrm{Ply}$ thickness $(\mathrm{mm})$ & 0.1524 & 0.1905 & 0.1524 & 0.1905 \\
\hline
\end{tabular}


Table 2 Preliminary design and margins of safety

\begin{tabular}{|c|c|c|c|c|}
\hline \multirow[t]{2}{*}{ Structural component } & \multirow[t]{2}{*}{ Layup } & \multicolumn{3}{|c|}{ Margins of safety ${ }^{(1)}$} \\
\hline & & Strength & Buckling & Crippling \\
\hline Skin & {$\left[( \pm 45) / 0_{3} /( \pm 45) / 90_{2}\right] \mathrm{s}$} & 36.1 & 7.13 & \\
\hline Stiffener flange on skin & {$\left[( \pm 45) / 0_{3} /(0 / 90)\right] \mathrm{s}$} & 3.33 & & 0.63 \\
\hline Stiffener canted web & {$\left[( \pm 45) / 0_{2} /(0 / 90)\right] \mathrm{s}$} & 3.33 & & +0.00 \\
\hline Stiffener flange far fm skin & {$[( \pm 45) / 04 /( \pm 45)] \mathrm{s}$} & 2.60 & & 2.05 \\
\hline Stiffener & See individual flanges and web & & 4.29 (Column) & \\
\hline Panel & See skin and stiffener & & 6.18 & \\
\hline Fastener holes & {$\left[( \pm 45) / 0_{3} /( \pm 45) / 90_{2}\right] \mathrm{s}$} & Bearing: 1.72 & & \\
\hline
\end{tabular}

MS = Allowable/Applied -1 .

driven close to zero by the design. Interestingly, the skin strength failure margin is very high even though the bearing margin is much lower. This is because all the applied load is assumed to be transferred via the fasteners into the skin first and then into the stiffeners while the skin strength failure is for the part of the total load acting on skin alone (excluding the load carried by the stiffeners). This means that in order to save weight in the skin, plies can be removed from the layup in regions away from the attachment surrounding the panel where the margin is already zero. This was not done here. Also, use of plies other than $0,45,-45$ and 90 could lead to lower weight designs but this was also not done here to stay consistent with more traditional design practices.

It is now assumed that the panel of Fig. 1 has damage covering a region which is approximately elliptical in shape. Two different cases are considered: (a) A smaller damage $100 \mathrm{~mm}$ long (along the stiffener axis) and $80 \mathrm{~mm}$ wide and (b) A bigger damage $150 \mathrm{~mm}$ long by $330 \mathrm{~mm}$ wide. In the first case, the damage is assumed to be centered over one stiffener. In the second case, the damage is centered at the skin between stiffeners but the two adjacent stiffeners are damaged. The damage sizes may appear arbitrary but are in line with reported damage sizes for holes, delaminations and cracks. A summary of such damage in [19] based on [1] shows that the damage sizes considered here cover $14 \%$ of holes, $58 \%$ of delaminations, and $40 \%$ of cracks found in service.

\section{Case A: $100 \mathrm{~mm} \times 80 \mathrm{~mm}$ Damage Centered over one Stiffener}

The situation is shown in Fig. 2. The repair patch consists of a scarf plug for the skin and a patch for the stiffener. Both are bonded to the panel and to each other with adhesive. In general, the repair must restore the structure to at least the same strength as before damage occurred. One very important consideration, often overlooked, is that the stiffness should be the same as the original stiffness. If it is lower, load is diverted around the repair to adjacent structure which may not have been designed for that. This is another reason why some of the margins in the design of the parent structure were purposefully kept somewhat higher than usual. If the stiffness of the repair is higher, the repair attracts more load than the original structure in that region. This means the repair must be designed to a higher load but also the transition region between the parent structure and the repair will see higher loads which must be accounted for. In the present repair design, the repair patches for the skin and stiffener have layup identical to the parent structure in order to match the stiffness. 


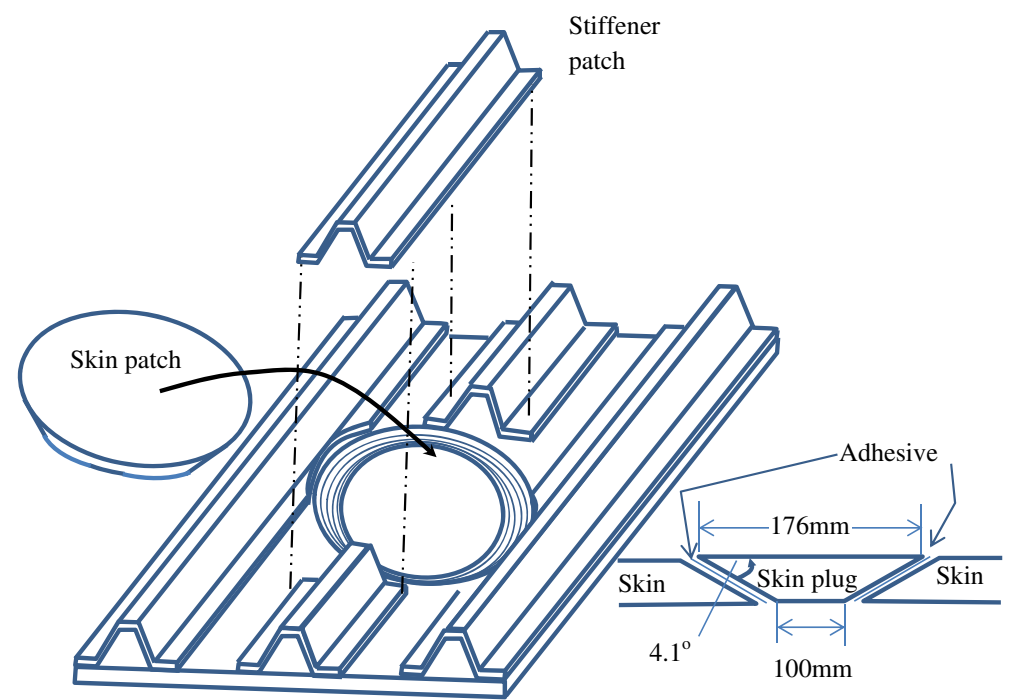

Skin plug after repair

Fig. 2 Repair patch with one stiffener damaged (only portion of entire panel shown)

A scarfed repair is selected for the skin in order to not disrupt the outside aerodynamic surface. The optimum scarf angle $\theta$ is the one which ensures that the adhesive fails at the same time as the adherends. This translates to [20]:

$$
\theta=\tan ^{-1}\left(\frac{\tau_{p}}{\sigma_{u l t}}\right)
$$

where $\tau_{\mathrm{p}}$ is the ultimate adhesive shear stress, assuming the adhesive is elastic-perfectly plastic, and $\sigma_{\text {ult }}$ is the ultimate strength of the stiffest adherend.

In the present case, both patch and skin of the parent structure are assumed identical so $\sigma_{\mathrm{ult}}$ is taken to be the first ply failure strength of the skin laminate in Table 2. Using the Tsai-Wu failure criterion, that value, in compression, is $480 \mathrm{MPa}$. For an aerospace grade adhesive with $\tau_{\mathrm{p}}=34.5 \mathrm{MPa}, \theta$ turns out to be 4.1 degrees. Using this angle and accounting for the different thicknesses in the skin-only versus the skin-plus-stiffener portion of the plug (see Fig. 2), an elliptical plug is created with length $176 \mathrm{~mm}$ (parallel to the stiffeners) and width $153 \mathrm{~mm}$ (perpendicular to the stiffeners). The thickness of the plug varies from $2.286 \mathrm{~mm}$ in the skin region to $3.962 \mathrm{~mm}$ in the regions replacing stiffener flange and skin.

Since the skin patch has the same layup as the original skin, only the adhesive strength must be checked. Following [20], it can be shown that for identical adherends, the strength of the joint expressed in terms of the average adhesive shear stress is:

$$
\tau_{a v}=\tau_{p}
$$

where the adhesive is modelled as elastic-perfectly-plastic as shown in Fig. 3.

The solution in [20] is for a two-dimensional scarf joint while the repair patch here is elliptical in shape. The axial compressive load that must be transferred through the patch becomes shear load in the adhesive. Over half the patch, a schematic of the shear stresses in the adhesive are shown in Fig. 4 with the arrows indicating approximate direction and magnitude. These stresses are transferred through the other half of the patch to the other side of the skin. Using the lowest half circumference of the patch $\mathrm{w}$ and the lowest scarf length $\ell$ the average 
Fig. 3 Adhesive shear stressstrain curve and elastic perfectly plastic approximation

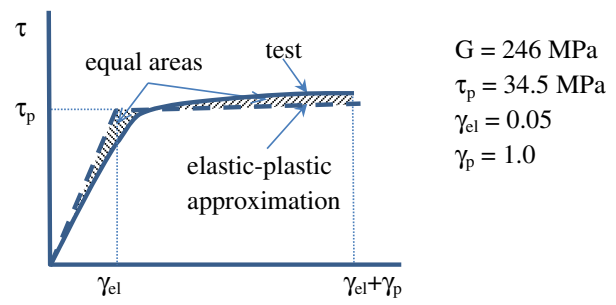

shear stress transferred across the patch is given by:

$$
\tau_{a v}=\frac{P}{w \ell}
$$

where $\mathrm{w}$ and $\ell$ are shown in Fig. 4 and are given by:

$$
w \simeq \sqrt{\frac{\left(\frac{a}{2}\right)^{2}+\left(\frac{b}{2}\right)^{2}}{2}}=\sqrt{\frac{\left(\frac{100}{2}\right)^{2}+\left(\frac{80}{2}\right)^{2}}{2}}=142.2 \mathrm{~mm}
$$

with $\mathrm{a}$ and $\mathrm{b}$ the major and minor axes of the smaller ellipse formed by the repair patch, and

$$
\ell=\frac{t}{\sin \theta}=\frac{2.286}{\sin (4.1)}=32 \mathrm{~mm}
$$

Using Eqs. (3) through) (5) to substitute in Eq. (2), the maximum load that can be transferred by the patch is given by:

$$
P_{\text {fail }}=\tau_{p} w \ell=157 k N
$$

This value comfortably exceeds the total applied load of $62 \mathrm{kN}$ so the repair patch and the adhesive will not fail. It should be noted that the calculation in Eq. (6) is conservative as only a portion of the available half area of the patch is used; The half area of the patch is approximately $15 \%$ greater than the product $\mathrm{w} \ell$. In addition, the load $\mathrm{P}$ that the patch must transfer is only a fraction of the total applied load. With reference to Fig. 2, the total load to be transferred is that corresponding to the skin of two bays and one stiffener. The load in two skin bays is:

$$
P_{s 2 b}=\frac{1}{3} P_{\text {skin }}
$$

Fig. 4 Load transfer across skin patch

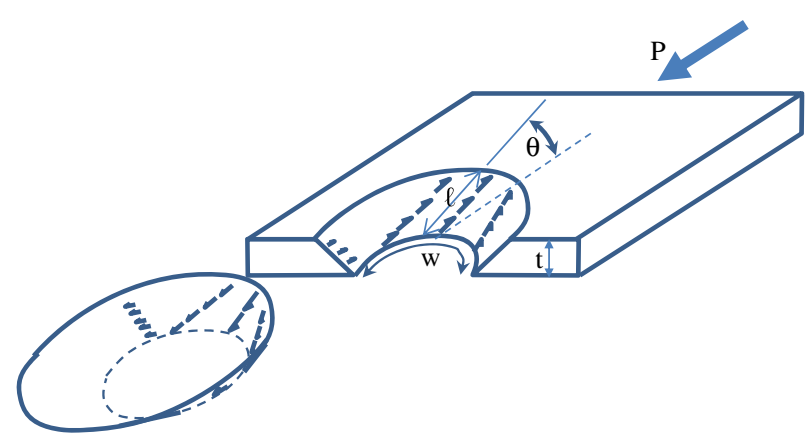


with the total skin load $\mathrm{P}_{\text {skin }}$ obtained from strain compatibility:

$$
P_{\text {skin }}=\frac{(E A)_{\text {skin }}}{(E A)_{\text {skin }}+(E A)_{\text {stiffeners }}} P
$$

Substituting values in Eqs. $(7,8)$, gives $\mathrm{P}_{\mathrm{s} 2 \mathrm{~b}}=10 \mathrm{kN}$. Combining this with the patch capability estimated in Eq. (6) gives a high safety margin for the skin patch equal to:

$$
M S_{\text {skinpatch }}=\frac{157}{10}-1=14.7
$$

The load carried by the stiffener to be repaired will be carried by the stiffener patch (see Fig. 2). As already mentioned the stiffener patch has the exact same layup as the stiffener in order to match the stiffener stiffness. This means that the strength and crippling margins are the same as before. As long as the overlap between the patch and the parent stiffener is sufficiently long, there will be no failure of the adhesive used to bond the two.

The stiffener joint can be analysed as a lap joint consisting of the two canted webs and the two flanges. The strain compatibility Eq. (8) applied to the stiffener members gives:

$$
F_{\text {mem }}=\frac{(E A)_{\text {mem }}}{\sum_{\text {allmembers }}(E A)_{\text {memi }}} F_{\text {stiffener }}=\frac{(E A)_{\text {mem }}}{\sum_{\text {allmembers }}(E A)_{\text {memi }}} \frac{1}{7} \frac{7(E A)_{\text {stiffener }}}{\left(7(E A)_{\text {stiffener }}+(E A)_{\text {skin }}\right)} P_{\text {total }}
$$

The membrane stiffnesses EA for the skin and each stiffener are found to be $161 \mathrm{MN}$ and 24.5 MN respectively. For the flange next to skin, canted web, and flange away from skin, the membrane stiffnesses are found to be $311 \mathrm{MN}, 6.83 \mathrm{MN}$ and $4.66 \mathrm{MN}$ respectively. Substituting values in Eq. (9), the most highly loaded members are the canted webs with an applied load of $1270 \mathrm{~N}$ on each. These would require the longest overlap so this load is used to determine the overlap for the entire stiffener patch. The same adhesive as in Fig. 3 is used.

Using standard lap joint analysis [21], for up to moderate overlaps, the strength of the joint measured by the average shear stress in the adhesive $\tau_{\mathrm{av}}$ is given by:

$$
\frac{\tau_{a v}}{\tau_{p}}=\ell_{1} \sqrt{\frac{2 G}{t_{s} E t}}
$$

with $\ell_{1}$ the overlap length, $\mathrm{t}_{\mathrm{s}}$ the adhesive thickness, and $\mathrm{E}$ and $\mathrm{t}$ the Young's modulus and thickness of the adherend. The average shear stress in this case is given by:

$$
\tau_{a v}=\frac{F_{m e m}}{b_{m} \ell_{1}}
$$

with $b_{m}$ the width of the most highly loaded flange and $F_{m e m}$ the corresponding force. Combining Eqs. $(10,11)$ and solving for the overlap $\ell_{1}$ gives:

$$
\ell_{1}=\sqrt{\frac{F_{m e m}}{b_{m} \tau_{p} \sqrt{\frac{2 G}{t_{s} E t}}}}
$$


Substituting values (with $\mathrm{b}_{\mathrm{m}}=56.05 \mathrm{~mm}, \mathrm{t}_{\mathrm{s}}=0.5 \mathrm{~mm}, \mathrm{E}=88.8 \mathrm{GPa}$ and $t=1.372 \mathrm{~mm}$ ) gives $\ell=2.71 \mathrm{~mm}$. This is a very small value and does not account for potential subsequent damage, material scatter and environmental effects on the adhesive properties shown in Fig. 3. It also does not account for any fatigue issues with the adhesive. Considering that a typical strength knockdown accounting for environment and material scatter is on the order of $50 \%$ (paste adhesives between room temperature and $70-80{ }^{\circ} \mathrm{C}$ ), a factor of 3 reduction of $\tau_{\mathrm{p}}$ to include effects of subsequent damage, gives an overlap value of $4.69 \mathrm{~mm}$. As not sufficient data are available on the adhesive to be used, an overlap of $25 \mathrm{~mm}$ is selected. Using Eqs. (10, 11) gives a force to fail the adhesive in the canted web of $159 \mathrm{KN}$ which exceeds the applied load of $1270 \mathrm{~N}$ by a very comfortable margin.

\section{Case B: $150 \mathrm{~mm} \times 330 \mathrm{~mm}$ Damage Centered in the Middle of a Skin Bay}

The situation is shown in Fig. 5. The design procedure is identical to that for Case A and is omitted here. The repair using the adhesive of Fig. 3 is shown to have comfortable positive margins for both the skin patch and the two patches for the stiffeners.

\section{Cost of Composite Structure and Repair(S)}

The fabrication cost for both the parent structure and the repair are estimated for two types of fabrication methods. The first is the traditional hand layup of prepreg material with no automation. The second is an automated variant of the process where the skin is cut and laid down by some robot (e.g. fiber placement or tape placement machine) and the stiffener fabrication is also automated. The latter is not entirely clear as one of the most efficient stiffener fabrication methods, pultrusion would not be able to fabricate the present design because fabric plies cannot be pultruded and fiber orientations other than 0 degrees cannot be used unless placed by hand. Be that as it may, it is assumed that an automation method for the stiffeners is available with cost savings similar to those achieved with pultrusion.

The fabrication cost does not include material cost and scrap nor anything extra for fatigue, machine maintenance or other overhead. The focus is the direct labor hours involved in fabrication. The process steps for both hand layup and the automated process are shown in Table 3 for the parent structure and the repairs.

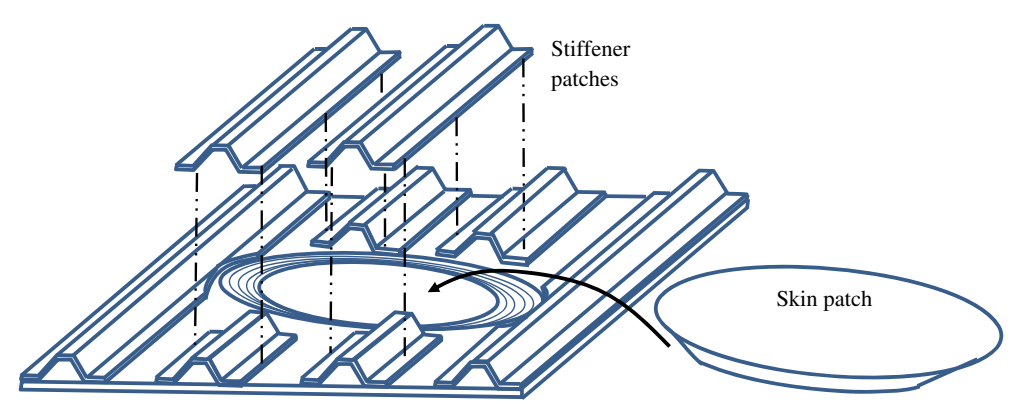

Fig. 5 Repair patch with two stiffeners damaged (only portion of entire panel shown) 
Table 3 Process steps for fabrication of stiffened panel and repairs

\begin{tabular}{ll}
\hline Stiffened panel & Repairs \\
\hline Set-up & Set-up \\
Cut and layup skin plies & Cut and layup plies for skin patch \\
Cut and layup stiffener plies & Cut and layup plies for stiffener patch(es) \\
Debulk & Debulk \\
Trim before cure & Trim before cure \\
Cure & Cure \\
Trim & Trim \\
Drill & Drill \\
Handling & Handling \\
Assembly & Cut and trim parent structure \\
& Bond patches to parent structure \\
\hline
\end{tabular}

A brief description of the steps follows:

Set-up: Includes locating and setting up templates, ply-books, and preparing any tools aiding in fabrication.

Cut and layup: For the case of stiffeners, bending material around corners is also included in the estimate. This is a function of the type of tooling used (concave or convex) with concave tooling having a much higher cost associated with it because bending plies into a tight radius and making sure they conform to that radius over the entire length, requires extra effort. It is assumed that all four of the corners of the hat stiffener are formed on convex tooling as shown in Fig. 6. Removable mandrels are placed inside the stiffeners during cure (a small draught angle is used to facilitate removal).

Debulk: Assumed to be done every four skin or stiffener plies

Trim before cure: Depending on the accuracy of placing plies in the mold, some trimming may be required before cure.

Cure: This does not include the actual cure time as it is usually book-kept separately (for example many parts may be cured together and the cure time is divided among them, or the cure time is directly included in factory overhead). It does include bagging, time to set up the autoclave, install thermocouples set up temperature charts, select cure cycle, etc. and then disconnect cure-related equipment, remove bag, collect and review temperature/ pressure records, etc.

Trim: Trim and sand to final dimensions using portable tools.

Fig. 6 Tooling approach used for hat stiffeners

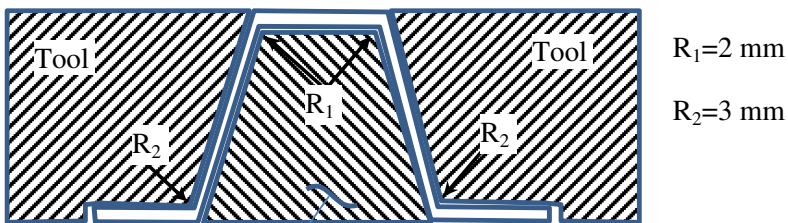

Mandrel is present

during cure 
Drill: Drill holes for attaching to next assembly. If the $2 \mathrm{~m} \times 1 \mathrm{~m}$ panel is made in multiple parts or modules, it includes drilling holes for attaching the sub-parts together.

Handling: Handling fixtures, templates and the part(s) during different operations.

Assembly: Cost of installing Hi-Lok fasteners when modules are used to make the $2 \mathrm{mx} 1 \mathrm{~m}$ panel

Cut and trim parent structure: Use hand-held equipment to remove damaged portion of the panel.

Bond patches to parent structure: Clean, prepare surfaces, apply adhesive, connect and hold/clamp parts to be bonded.

Adding up the total fabrication time across all steps gives the total fabrication time. Here, the cost equations in [10] are used. They are convenient because, irrespective of the step considered, they always have the form:

$$
C=C_{o}+{ }^{o} C_{1} P^{\alpha}+C_{2} A^{\beta}
$$

where $\mathrm{C}$ is the cost of the step or sub-step in hours, $\mathrm{C}_{\mathrm{o}}$ is a set-up time (if applicable), $\mathrm{C}_{1}$ and $\mathrm{C}_{2}$ are constants specific to the step considered, $\mathrm{P}$ and $\mathrm{A}$ are the perimeter and area of the part, ply, bag, mold being handled, and $\alpha$ and $\beta$ are constants specific to the process step being analysed. Depending on the step, any of $\mathrm{C}_{\mathrm{o}}, \mathrm{C}_{1}, \mathrm{C}_{2}, \alpha$, and $\beta$ can be zero. Values for these constants for different steps and different ways of carrying out the same step (e.g. by hand or with automated equipment) can be found in [10]. In addition, the cost equations in [10] have been verified by a large amount of data and by other models [11, 12].

It is important to note that the equations used here assume a fully-learned process. This means that no learning curve effects are applicable. Any cost reductions resulting from improvements incorporated in the various steps or efficiency increases on the part of the operators have already been factored in.

For hand layup, two possibilities can be distinguished: (a) The part is an isolated "one-off" part without pre-planning which would take into account multiple part production (b) Provisions are made for multiple identical parts being manufactured. In the first case, there are no efficiencies realized by avoiding multiple set-ups for example where the same step for different parts can be carried out with one set-up. In addition, cutting a ply is done without considering that the edge of one ply could be the edge of the same ply in another part which would reduce the number of edges cut. Similarly, stiffeners can be made longer than is needed for one part and cut to size and so on. Obviously, in the second case where advance planning increases efficiency, the cost will be significantly lower.

Using Eq. (13), the cost of the entire hat-stiffened panel is estimated for the "one-off" and the "multiple-parts" possibilities. The results are shown in Fig. 7. In addition, the cost estimate when the fabrication is fully automated is also shown in Fig. 7.

Irrespective of the selected fabrication approach, the cost of cutting and laying up the stiffeners is the biggest contributor taking up $62 \%, 61 \%$, and $53 \%$ of the total for each of the three approaches shown in Fig. 7. It is followed by "assembly" at 13 to $22 \%$ of the total. Assembly here corresponds to drilling $5 \mathrm{~mm}$ diameter holes at $20 \mathrm{~mm}$ spacing all around the edge of the component. This assembly cost is essentially the same for all cases as the steps to locate, pre-drill, drill and counterbore holes remains the same. The next biggest process step changes with process. In the "one-off" case is debulking at $9.1 \%$ of the total while for the cases 


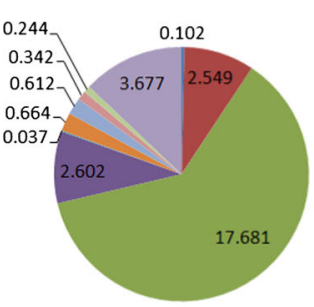

"One-off"

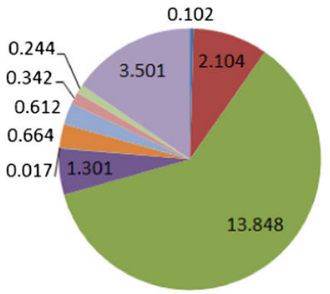

Planning multiple parts $22.7 \mathrm{hrs}$

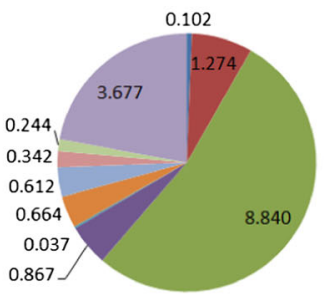

Fully automated

$16.7 \mathrm{hrs}$
- Setup

- Cut\& layup skin

w Cut\& layup stiffeners

- Debulk

- Trim bcure

m Prep cure

- Cure

in Trim

II Handling

assembly

Fig. 7 Fabrication cost for entire panel

with "economies in numbers" or full automation, it is the cutting and layup of the skin plies at 9.2 and $7.6 \%$ respectively.

In a similar manner, the cost of the two repair cases can be estimated. The repair cost is estimated as a "one-off" part. This is done for two reasons. First, repairs are expected to be quite infrequent and second, the (average) repair center doing the repair is not expected to have at its disposal the multiple robotic equipment assumed for a fully-automated cost estimate. The cost estimates for the two repairs are shown in Fig. 8.

It is seen from Fig. 8 that cut and layup of plies takes up more than half the cost for each patch followed by the bonding step which ranges from $8.7 \%$ for the skin patch in Case A to $18.9 \%$ for the stiffener patch in the same case. It is interesting to note that the repair times in

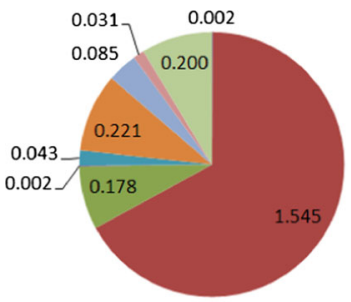

Skin patch

$2.31 \mathrm{hrs}$

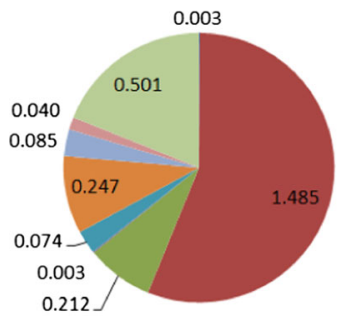

Stiffener patch

$2.65 \mathrm{hrs}$

CASE A

Total: $4.96 \mathrm{hrs}$

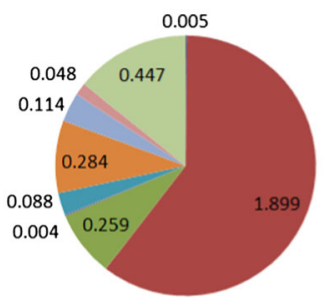

Skin patch

$3.15 \mathrm{hrs}$

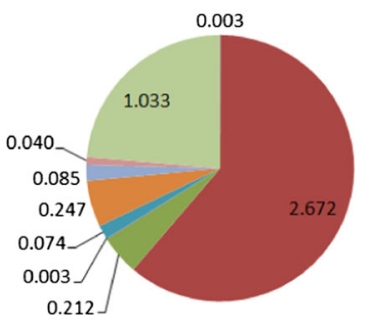

Stiffener patch

8.74 hrs

CASE B

Total: $11.89 \mathrm{hrs}$
Prep time

- Cut\&layup

nebulk

- Trim b cure

Bag

nure

- Trim

Handling

Bond patch

Fig. 8 Repair cost for damage in skin and one stiffener (Case A) or in skin and two stiffeners (Case B) 
Fig. 8 are in line with values reported by Gary and Riskalla in [1] where one airline representative reported that after inspection and repair definition, a major repair takes $8 \mathrm{~h}$ to complete.

Several comments should be made in order to put these repair times in perspective. As can be seen from the skin patch taper in Figs. 2 and 5, access to the structure to be repaired is assumed from the inside. If access were only available from the outside, which would be the case of most wing skin repairs, then the cost of the repairs would increase significantly. Bigger cutouts would be needed, and it would be hard to bond the stiffener plug(s) and afterwards the skin plugs from the outside. Holding the patches in place and applying pressure would be difficult. In addition, the bondline thickness would not be controlled as accurately with potential implications for the patch designs (cost and weight increase). Such increases in the cost of the repair result in a lower number of repairs per part needed for the modular design to have the same total cost as the single part design (see next section).

Another point of interest is the weight of the repair which, in this discussion was completely omitted. As the exact same materials and layups are used for the patches as for the parent structure, the weight increase due to the repairs would be only due to the weight of the adhesive and the overlaps. This would not be the case if lower cost materials were used as would be the case for a wet layup. While the cost of a wet layup repair would be lower and equipment and materials would be more readily available at the station making the repair, the increase in weight over the repairs proposed here would be significant. The fiber volume would be lower and more material would be needed. Furthermore, it would be very difficult to match the stiffness of the parent structure as the resulting stiffness of such a repair is hard to calculate accurately.

\section{Remove and Replace Option - Implications for Life-Cycle Cost}

Instead of making a special purpose repair each time there is damage in the structure, it is possible to make the structure modular and use individual modules to replace the damaged part. This assumes that the modules are fastened together for easy removal and replacement. The modular structure has a lot of advantages in terms of reducing non-recurring and, in some cases, recurring cost $[16,22]$. It may increase the weight by a small amount but the reductions in cost may justify that increase. For example, depending on how modularity is implemented, cost reductions in the range $30-50 \%$ can be achieved with a 5\% increase in weight. It is, therefore, worth investigating how replacing a module would affect the cost of a repair. This approach also has the advantage of eliminating "one-off" repairs. Every time there is damage, which can be of different sizes and types, a different repair would be designed which requires planning and approvals from authorities and the manufacturer. This could add significantly to the down time of an aircraft as opposed to simply replacing the damaged region with a new component.

In the present example, the entire panel was assumed to be designed by a single load case and the load was constant throughout the panel. As a result, the modular design and manufacturing of the component will have only a very small weight increase due to the use of fasteners at the connections and from the extra joggled regions in the skin and stiffener doublers where modules are fastened together. This is shown in Fig. 9.

The following possibilities are considered: (a) The component is made of two identical parts, each $1 \mathrm{~m}$ long by $1 \mathrm{~m}$ wide. (b) The component is made of four identical parts each 

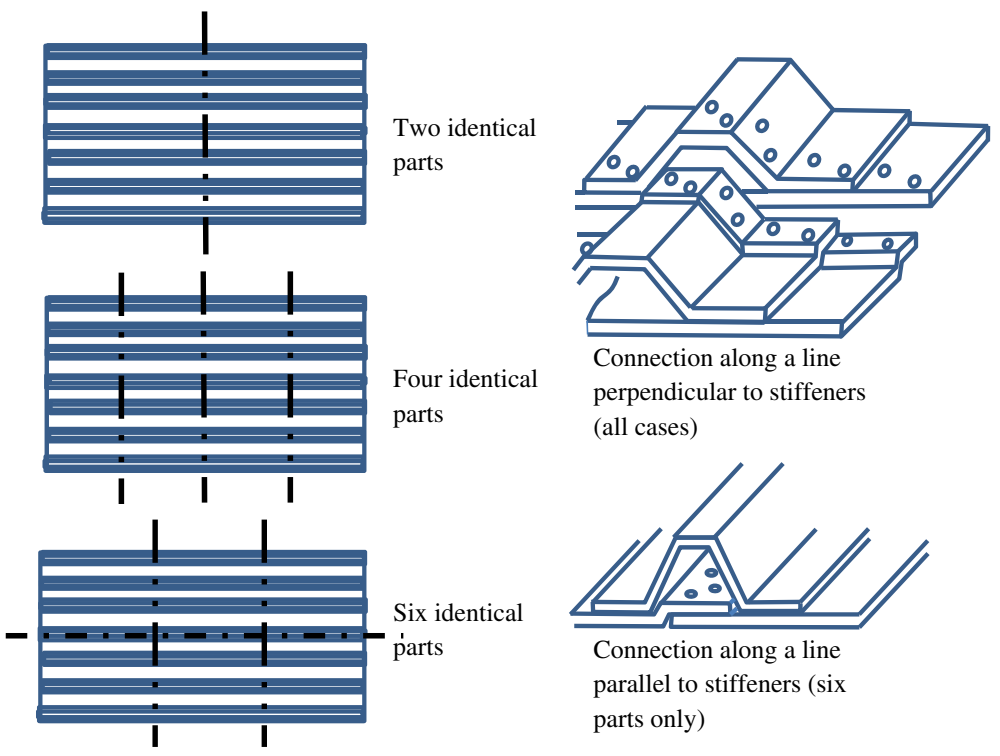

Fig. 9 Division of panel in identical parts or modules

$0.5 \mathrm{~m}$ long by $1 \mathrm{~m}$ wide, and (c) The component is made of six identical parts, each $0.67 \mathrm{~m}$ long by $0.5 \mathrm{~m}$ wide. The options are shown in Fig. 9. The connections between parts are not designed here in detail. Concepts of how they could be done are also shown in Fig. 9.

The case of six parts merits some attention as it helps show how design considerations can affect ease of repair, in addition to the considerations mentioned earlier. The division is done as shown in Fig. 9, as opposed to one cut perpendicular to the stiffeners in the middle of the panel and two cuts parallel to the stiffeners, because this ensures that a stiffener is along the connection line parallel to the loading direction thus providing a stiff and strong support. More importantly, to maintain the outside aerodynamic surface, the skin joggle shown at the bottom right of Fig. 9 must be fully enclosed in the stiffener. If not, one of the flanges must be shifted up in Fig. 9 to accommodate the extra length of the joggled portion of the skin. Then, the stiffener is unsymmetric and it will be different than all other stiffeners requiring extra tooling and fabrication hours. To avoid this and retain commonality, the distance between the canted webs at the bottom must be long enough to accommodate the fasteners. If the two fastener rows are staggered as shown at the bottom right, a 4D fastener spacing and a 2.5D edge distance on either side with $D$ the fastener diameter results in a joggle width of 39-40 mm when $\mathrm{D}=5 \mathrm{~mm}$. From Fig. 1, the available space at the bottom of the hat stiffener is $72 \mathrm{~mm}$ which is more than sufficient.

The cost of each option, with 1, 2, 4, or 6 parts making up the panel is determined using the same procedures as in the previous section. For the multi-part cases, the assembly cost includes fastener installation along the lines where the individual parts connect with each other. The cost estimates are shown in Table 4 for the case where multi-part production is included in the planning (more efficient than one-off fabrication) labelled "efficient hand layup" and for the fully automated fabrication case. Both the cost of a single module and the entire panel made by identical modules are shown. The cost of the single module is obtained by dividing the cost of the entire panel by the number of modules used. 
Table 4 Cost of panel when made of identical sub-components

\begin{tabular}{|c|c|c|c|c|}
\hline \multirow[t]{2}{*}{ Number of modules } & \multicolumn{2}{|c|}{ Efficient hand layup (hrs) } & \multicolumn{2}{|c|}{ Automated fabrication (hrs) } \\
\hline & Single module & Entire panel & Single module & Entire panel \\
\hline 1 & 22.7 & 22.7 & 16.7 & 16.7 \\
\hline 2 & 16.0 & 32.0 & 9.6 & 19.2 \\
\hline 4 & 9.35 & 37.4 & 5.88 & 23.5 \\
\hline 6 & 7.47 & 44.8 & 4.67 & 28.0 \\
\hline
\end{tabular}

The results in Table 4 reproduce the well-known trend where the cost of a part is lower when made with as few sub-parts as possible. It should be noted that these results are with fully- learned fabrication processes. It is possible that a factory which is very efficient in assembly of parts and at the beginning of a steep learning which would be the case for processes dominated by human labor, splitting a part into smaller modules will result in lower cost due to learning curve reductions $[16,22]$. This effect is not included here.

What is of interest, however, is the total cost that will be incurred if the part fabricated needs to be repaired over its lifetime a number of times. If the panel is repaired using the one-off repairs for cases A and B in the previous section, the cost of each repair may be higher than the cost of removing and replacing one of the modules out of which the panel is made. This means that if the panel is to be repaired enough times the total cost will be higher than removing and replacing the corresponding modules.

The total cost $\mathrm{C}_{\text {tot }}$ of fabricating the panel and then, every time there is damage (which could be at different locations in the panel) doing a separate "one-off" repair is given by:

$$
C_{\text {tot }}=C_{\text {panel }}+n C_{\text {rep }}
$$

where $\mathrm{C}_{\text {panel }}$ is the panel cost and changes with the number of modules or identical sub-parts used to make it, $\mathrm{n}$ is the number of times a repair is done over the lifetime of the part and $\mathrm{C}_{\mathrm{rep}}$ is the cost of the repair, obtained from Fig. 8 for Case A and Case B.

For the case where the panel is made from identical modules, the cost of the panel is the number of modules times the cost of each module and the cost of the repair is the cost of a single module:

$$
C_{\text {tot }}=N C_{\text {mod }}+n C_{\text {mod }}
$$

where $\mathrm{N}$ is the number of modules making up the part (2, 4, or 6 in the present application) and $\mathrm{C}_{\text {mod }}$ is the cost of each module given in Table 4.

Comparing Eqs. $(14,15)$ it can be seen that even though $\mathrm{NC}_{\text {mod }}$ is usually greater than $\mathrm{C}_{\text {panel }}$, if $\mathrm{C}_{\text {mod }}$ is lower than $\mathrm{C}_{\text {rep }}$ there will be a number $\mathrm{n}$ after which the total cost given by Eq. (15) will be lower than that given by Eq. (14). This can be found by equating the right hand sides of Eqs. $(14,25)$ and solving for $n$ :

$$
n=\frac{N C_{\text {mod }}-C_{\text {panel }}}{C_{\text {rep }}-C_{\text {mod }}}
$$

If the numerator is positive, i.e. the cost of making the panel in modules is higher than making it as one piece, then the number $\mathrm{n}$ of repairs beyond which it pays to make the panel in modules can be found as long as the denominator is positive, i.e. the cost of a one-off repair is 
greater than the cost of a single module. This requirement that $\mathrm{C}_{\mathrm{rep}}>\mathrm{C}_{\mathrm{mod}}$ can be used to determine the number of modules needed for the modular solution to give lower total cost over the life of the part. At the same time, $n$ must be representative of the expected times the part will be repaired. Some parts are repaired more often than others because they are exposed to runway debris, impacts during luggage loading and unloading, hail damage, tool drops during maintenance, etc. For such parts, $n$ will be large enough that the modular approach will offer an advantage.

This trade-off between modular and single piece construction and the resulting value of $n$ can be seen graphically in Figs. 10 for repair Case A and 11 for repair Case B. Eqs. $(14,15)$ are used along with the cost values of Table 4.

The non-automated fabrication (but with multiple part planning to eliminate duplication) is shown in Fig. 10a. The lowest curve corresponds to making a targeted, "one-off" repair whenever there is damage. All other curves correspond to repairing by replacing the damaged module. As it can be seen from this Figure, there are no intersections between the lowest curve and the ones above it which means that, in this case, it is better (lower total cost) to make a special-purpose repair every time there is damage.
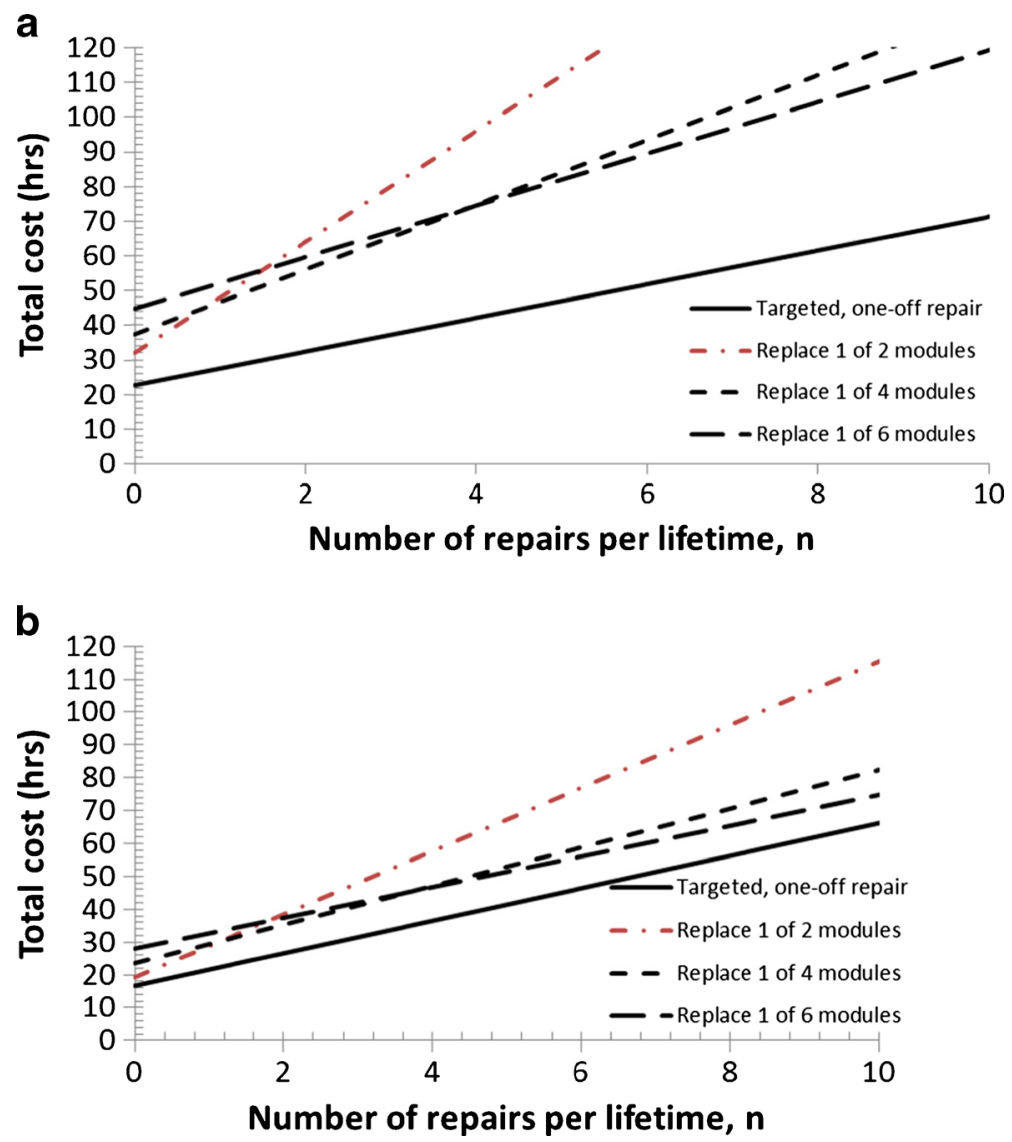

Fig. 10 Total cost of part fabrication and repairs for Case A (100 $\mathrm{mm} \times 80 \mathrm{~mm}$ damage) 
The situation for fully-automated fabrication is shown in Fig. 10b. Again, there are no intersections between the "one-off" repair curve and the module replace curves. However, the slope of the curve when the panel is made out of six modules is lower than the slopes of all other curves which means that it will intersect the "one-off" repair curve at a higher value of $n$. Using Eq. (16) this value turns out to be 39 repairs. While it is unlikely, it is not entirely impossible that some panels in the more exposed areas might see that number of repairs over their lifetime.

The non-automated fabrication for the repair size of Case B is shown in Figure 11a. In this case, using six modules is more economical than a single panel if the panel is to be repaired 5 times $(n=5.0)$. The four-module option intersects the "one-off" repair curve at $n=5.8$ indicating that after 6 repairs, this option too would be more economical. Dotted vertical and horizontal lines are included in Fig. 10 to indicate the number of repairs and the corresponding total cost.

The case where panel and module fabrication are fully automated and a repair corresponding to Case B is needed, is shown in Fig. 11b. In this case, all module replacement options
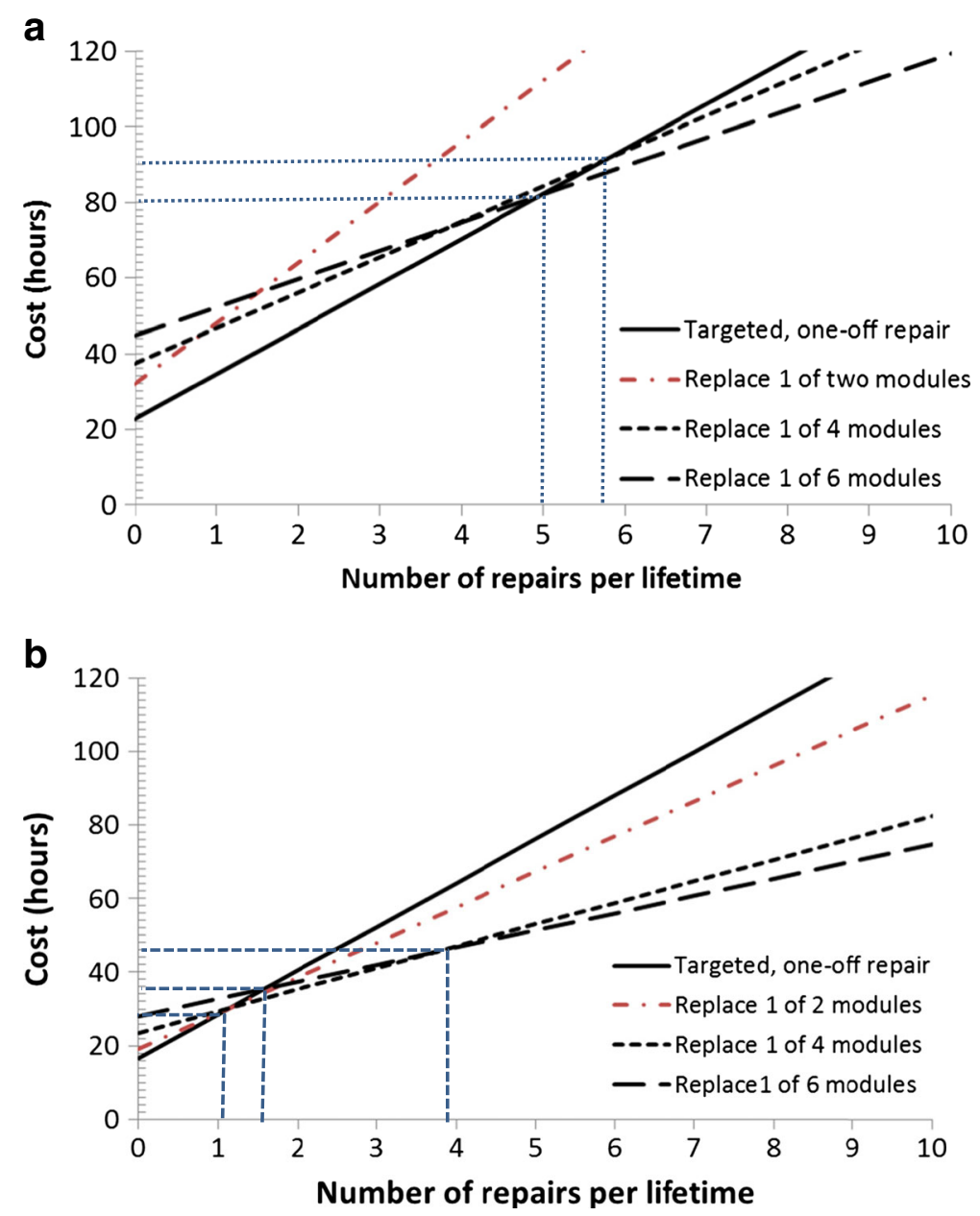

Fig. 11 Total cost of part fabrication and repairs for Case B $(150 \mathrm{~mm} \times 330 \mathrm{~mm}$ damage $)$ 
become more economical than the "one-off" repair. For two modules, $n=1.11$, for four modules, $n=1.13$, and for 6 modules, $n=1.56$. In all cases, after two repairs, it is more economical to use a modular panel. Dotted lines are included in Fig. 11b corresponding to these solutions. It is also very interesting that the four-module and six-module curves intersect each other after about 4 repairs. This means that if the anticipated number of repairs exceeds 4 , then making the panel out of six modules is the most economical solution.

\section{Discussion}

As might be expected as the process becomes fully automated it is more advantageous to make the panel out of smaller modules. This is because the targeted repair is expected to be fabricated by hand layup or similar non-automated process. The repairs are made infrequently and at maintenance stations where automated equipment is unlikely to exist. If, however, the repairs were also automated, then this conclusion would no longer be valid.

As the repair size increases, the number of repairs per lifetime required for a modular approach to be more economical, decreases. Conversely, for really small repairs, significantly smaller than the repair of Case A in this study, the modular approach will not give any benefits. The damage sizes used here are only two of the many possibilities. The trends will be similar for other repair sizes as long as they are larger than a minimum size where the modular approach would never be beneficial. Also, as the number of modules increases, the possibility of finding a number of repairs beyond which the modular approach is advantageous, increases. However, this break-even number of repairs $n$ also increases with the number of modules.

The approach described here should not be applied to all parts unless it can be shown convincingly that learning curve effects and reductions in non-recurring cost [16] justify such an approach. If multiple repairs are the only driver, then only panels susceptible to damage during service should be considered for this approach. Panels with no or very few repairs anticipated during service will cost significantly more if made from several modules.

The choice of fabrication method and the amount of automation used for both the panel modules and the repair itself determine whether there is a number of modules that can be used to minimize the total cost over the part lifetime. Including these repair-related considerations in the design process will help minimize the cost. In addition, the size and orientation of modules must allow for ease of repair. The margins of safety for the different failure modes should also facilitate repairs. For example, higher margins of safety for skin and stiffener strength result in higher thicknesses which facilitate optimum scarf angles and minimize patch overlaps which keep the weight close to a minimum.

\section{Conclusions}

A design approach accounting for modular construction which would facilitate repairs of composite stiffened skin structures was developed. Accounting for the cost of the structure allows optimization of the total cost of the panel including the repairs it may have to undergo over its lifetime. It was shown that there is a break-even number of repairs beyond which it is more economical to make the panel out of individual modules. The number of modules depends on the fabrication process selected (automated or non-automated) and the size of the damaged region to be repaired. For small damaged regions, a single panel or module and 
special purpose repairs are more economical. Beyond a certain damage size, using two, four, or six modules will lead to reduced total cost. The break-even point where the cost from the modular design is the same as the cost of a single part ranges from 2 to 39 repairs per part depending on the fabrication method selected and size of damage. Given that at least one panel per aircraft per year will be damaged and the life of today's aircraft is around 30 years, this range makes considering the modular approach a worthwhile endeavor.

Open Access This article is distributed under the terms of the Creative Commons Attribution 4.0 International License (http://creativecommons.org/licenses/by/4.0/), which permits unrestricted use, distribution, and reproduction in any medium, provided you give appropriate credit to the original author(s) and the source, provide a link to the Creative Commons license, and indicate if changes were made.

\section{References}

1. Gary, P.M., and Riskalla, M.G., "Development of Probabilistic Design Methodology for Composite Structures", Report no DOT/FAA/AR-95/17, 1997.

2. Soutis, C., Duan, D.M., Goutas, P.: Compressive behavior of CFRP laminates repaired with adhesively bonded external patches. Compos Struct. 45(4), 289-301 (1999)

3. Campilho, R.D.S.G.: deMoura, M.F.S.F., and Domingues, J.J.M.S., "modelling single and double-lap repairs on composite materials". Compos Sci Technol. 65(13), 1948-1958 (2005)

4. Gunnion, A.J., Herszberg, I.: Parametric study of scarf joints in composite structures. Compos Struct. 75(1), 364-376 (2006)

5. Baker, A.: Bonded composite repair of fatigue-cracked primary aircraft structure. Compos Struct. 47(1), 431-443 (1999)

6. Wang, C.H., Gunnion, A.J.: Optimum shapes of scarf repairs. Compos Part A Appl Sci Manufacts. 40(9), 1407-1418 (2009)

7. Baldan, A.: Adhesively-bonded joints and repairs in metallic alloys, polymers and composite materials: adhesives, adhesion theories and surface pretreatment. J Mater Sci. 39(1), 1-49 (2004)

8. Tomblin, J.S., Salah, L., Welch, J.M., and Borgman, M.D., "Bonded Repair of Aircraft Composite Sandwich Structures", Report no DOT/FAA/AR-03/74, 2004.

9. Katnam, K.B., Da Silva, L.F.M., Young, T.M.: Bonded repair of composite aircraft structures: a review of scientific challenges and opportunities. Prog Aerosp Sci. 61, 26-42 (2013)

10. Lorenzana, J., LeBlanc, DJ., Kokawa, A., Bettner, T., and Timson, F., "Advanced Composite Cost Estimating Manual”, Vol II, Report no AFFDL-TR-76-87, 1976.

11. Gutowski, T.G., Hoult, D., Dillon, G., Mutter, S., Kim, E., Tse, M., Neoh, E.T.: Development of a theoretical cost model for advanced composite fabrication. Compos Manuf. 5(4), 231-239 (1994)

12. Gutowski, T.G., in Advanced Composites Manufacturing, T. Gutowski Ed., John Wiley \& Sons, 1997, chapter 13.4.

13. Gutowski, T., Henderson, R., Shipp, C.: Manufacturing costs for advanced composites aerospace parts. SAMPE J. 27(3), 37-43 (1991)

14. Kaufmann, M., Zenkert, D., Mattei, C.: Cost optimization of composite aircraft structures including variable laminate qualities. Compos Sci Technol. 68(13), 2748-2754 (2008)

15. Curran, R., Mullen, M., Brolly, N., Gilmour, M., Hawthorn, P., and Cowan S. "Cost modelling of composite aerospace parts and assemblies", in Collaborative product and service life cycle management for a sustainable world, Curran, R., Chou S-Y, and Trapper, A., Editors, Springer, 2008

16. van Gent, I., Kassapoglou, C.: Cost-weight trades for modular composite structure. Struct MultiDisciplinary Optimiz J. 931-952, (2014)

17. Hueber, C., Horejsi, K., Schledjewski, R.: Review of cost estimation: methods and models for aerospace composite manufacturing. Advanc Manufact: Polymer Compos Sci. 2(1), 1-13 (2016)

18. Kassapoglou, C.: Design and Analysis of Composite Structures, Wiley, 2nd edn, (2013)

19. Rusk, D.T., Lin, K.Y., Swartz, D.D., Ridgeway, G.K.: Bayesian updating of damage size probabilities for aircraft structural life-cycle management. J Aircr. 39(4), 689-696 (2002)

20. Hart-Smith, L.J.: Adhesive-bonded scarf and stepped lap joints. NASA CR. 112237, (1973)

21. Hart-Smith, L.J.: Analysis and design of advanced composite bonded joints. NASA CR. 2218, (1974)

22. Apostolopoulos, P., Kassapoglou, C.: Cost minimization of composite laminated structures-optimum part size as a function of learning curve effects and assembly. J Compos Mater. 36(4), 501-518 (2002) 